\title{
Editorial: Trematode Infection in Ruminants
}

\author{
Theo de Waal ${ }^{1 *}$ and Khalid Mehmood ${ }^{2}$ \\ ${ }^{1}$ School of Veterinary Medicine, University College Dublin, Dublin, Ireland, ${ }^{2}$ Faculty of Veterinary and Animal Sciences, The \\ Islamia University of Bahawalpur, Bahawalpur, Pakistan
}

Keywords: trematode infection, Fasciola, Paramphistomum, Schistosoma, one health-approach

\section{Editorial on the Research Topic}

\section{Trematode Infection in Ruminants}

Trematodes are a diverse group of parasites affecting both humans and animals health worldwide. One school of thought is that trematodes evolved from free-living flatworms (progenitors of present-day rhabdocoel turbellarians), became intimately associated with mollusks and, ultimately, developed into parasitic forms. Evolutionary divergence within this endoparasitic population gave rise to two subclasses, the Digenea and Aspidobothrea (1). The Digenea is one of the largest groups of platyhelminths and parasitises a wide range of invertebrate and vertebrate hosts which also includes humans. Within the vertebrate, final host, these worms are found in numerous organs, including the intestine, lungs, liver, and vascular system. Infections with these parasites are responsible for substantial production losses in the livestock industry and decrease in the quality-of-life in humans (2-6).

Fasciolosis causes substantial economic losses to pastoral agricultural communities and commercial animal farmers, estimated at US\$ 2 billion per year, through the death of infected cattle, liver condemnation, and productivity losses associated with reduced feed conversion quality. Fasciolosis is widespread in tropical areas, affecting up to $90 \%$ of cattle, and is considered the most significant helminth parasite (7). Fasciola hepatica infections are reported to affect weight gain, milk production, milk solids content and fertility of cattle $(8,9)$. More recent studies provided sound evidence that milk production in dairy cattle or carcass weight of slaughtered beef cattle in F. hepatica-infected herds was decreased on average by $3-5 \%$ or $0.5-0.7 \%$, respectively $(10,11)$.

Furthermore, fasciolosis is recognized as emerging disease in humans. The World Health Organization has anticipated that 180 million people are at risk of infection and 2.4 million people are infected with fasciolosis in more than 60 countries (https://www.who.int/foodborne trematode_infections/fascioliasis/en/). Fasciolosis in people is responsible for a decrease in the quality of life with the global burden of food-borne fasciolosis estimated 90,041 Disability Adjusted Life Years (12). The northern Bolivian Altiplano is one of the areas where the highest prevalence of $F$. hepatica in humans have been reported (13). Even at this high altitude $(>3,200 \mathrm{~m}$ above sea level) the parasite is capable of completing its life cycle with infection levels of $20.6-63.1 \%$ in cattle and sheep, respectively (Mas-Coma et al.).

With the increasing reports of anthelmintic resistance in F. hepatica (14) there are many research studies underway to find alternative control option including vaccination (15) and alternative drug options (14). One such option is protein kinase inhibitors which has been widely studied in Schistosoma spp. In the paper of Morawietz et al. the authors investigated two kinase inhibitors used in human cancer research: the Abelson tyrosine kinase (ABL-TK) inhibitor imatinib and the polo-like 1 (PLK1) inhibitor BI2536 as therapeutic targets in F. hepatica and have shown that both inhibitors had lethal effects on immature flukes but only imatinib was lethal in adult flukes. The results of phylogenetic analysis support the logical evolution of fasciolosis transmitted by planorbid 
snails, beginning in Africa and spreading to Asia and the rest of the Holarctic Region (16).

Although paramphistomes (rumen flukes) are generally considered of less importance in animal health there has been an increase incidence of infections in both cattle and sheep, in recent years, especially in Europe (17), sometimes leading to dramatic outbreaks $(18,19)$. More than 70 species of paramphistomes infecting animals, has been described but distinguishing between species morphologically is difficult and requires expertise. Accurate species identification is important if we aim to understand the epidemiology and host-parasite interaction of this diverse group of parasites better. Mitchell et al. described a universal approach to rumen fluke identification across species and hosts using molecular techniques. Schols et al. argue for the use of cytochrome c oxidase subunit I (COI)-based

\section{REFERENCES}

1. Bogitsh BJ, Carter CE, Oeltmann TN. Chapter 9 - General characteristics of the Trematoda. In: Bogitsh BJ, Carter CE, Oeltmann TN, editors, Human Parasitology. 5th ed. Oxford: Academic Press (2019). p. 14974. doi: 10.1016/B978-0-12-813712-3.00009-6

2. Fürst T, Keiser J, Utzinger J. Global burden of human food-borne trematodiasis: a systematic review and meta-analysis. Lancet Infect Dis. (2012) 12:210-21. doi: 10.1016/S1473-3099(11)70294-8

3. Mas-Coma S, Bargues MD, Valero MA. Fascioliasis and other plant-borne trematode zoonoses. Int J Parasitol. (2005) 35:125578. doi: 10.1016/j.ijpara.2005.07.010

4. Piedrafita D, Spithill TW, Smith RE, Raadsma HW. Improving animal and human health through understanding liver fluke immunology. Parasite Immunol. (2010) 32:572-81. doi: 10.1111/j.1365-3024.2010.01223.x

5. Qian MB, Utzinger J, Keiser J, Zhou XN. Clonorchiasis. Lancet. (2016) 387:800-10. doi: 10.1016/S0140-6736(15)60313-0

6. Walz Y, Wegmann M, Dech S, Raso G, Utzinger J. Risk profiling of schistosomiasis using remote sensing: approaches, challenges and outlook. Parasit Vectors. (2015) 8:163. doi: 10.1186/s13071-015-0732-6

7. Mehmood K, Zhang H, Sabir AJ, Abbas RZ, Ijaz M, Durrani $\mathrm{AZ}$, et al. A review on epidemiology, global prevalence and economical losses of fasciolosis in ruminants. Microb Pathog. (2017) 109:253-62. doi: 10.1016/j.micpath.2017.06.006

8. Black NM, Froyd G. The possible influence of liver fluke infestation on milk quality. Vet Record. (1972) 90:71-2. doi: 10.1136/vr.90.3.71

9. López-Díaz MC, Carro MC, Cadórniga C, Díez-Baños P, Mezo M. Puberty and serum concentrations of ovarian steroids during prepuberal period in Friesian heifers artificially infected with Fasciola hepatica. Theriogenology. (1998) 50:587-93. doi: 10.1016/S0093-691X(98)00163-0

10. Sanchez-Vazquez MJ, Lewis FI. Investigating the impact of fasciolosis on cattle carcase performance. Vet Parasitol. (2013) 193:307-11. doi: 10.1016/j.vetpar.2012.11.030

11. Charlier J, Vercruysse J, Morgan E, van Dijk J, Williams D. Recent advances in the diagnosis, impact on production and prediction of Fasciola hepatica in cattle. Parasitology. (2014) 141:326-35. doi: 10.1017/S0031182013001662

12. Torgerson PR, Devleesschauwer B, Praet N, Speybroeck N, Willingham AL, Kasuga F, et al. World health organization estimates of the global and regional disease burden of 11 foodborne parasitic diseases, 2010: a data synthesis. PLoS Med. (2015) 12:e1001920. doi: 10.1371/journal.pmed.1001920 barcoding as an important key part of the interagive taxonomy for trematodes and they successfully identified trematodes ion both the snail intermediate host as well as in the definitive animal host.

Overall, this Research Topic provide a brief review of the current research relating to trematode infection ultimately improving our understanding and providing new strategies to control trematode diseases.

\section{AUTHOR CONTRIBUTIONS}

TW wrote the first draft of the manuscript. KM revised and added additional text to the final manuscript. All authors contributed to the article and approved the submitted version.

13. Mas-Coma S, Angles R, Esteban JG, Bargues MD, Buchon P, Franken M, et al. The Northern Bolivian Altiplano: a region highly endemic for human fascioliasis. Trop Med Int Health. (1999) 4:454-67. doi: 10.1046/j.1365-3156.1999.00418.x

14. Kelley JM, Elliott TP, Beddoe T, Anderson G, Skuce P, Spithill TW. Current threat of triclabendazole resistance in Fasciola hepatica. Trends Parasitol. (2016) 32:458-69. doi: 10.1016/j.pt.2016.0 3.002

15. Molina-Hernández V, Mulcahy G, Pérez J, Martínez-Moreno Á, Donnelly S, O’Neill SM, et al. Fasciola hepatica vaccine: we may not be there yet but we're on the right road. Vet Parasitol. (2015) 208:101-11. doi: 10.1016/j.vetpar.2015.0 1.004

16. Mera y Sierra R, Artigas P, Cuervo P, Deis E, Sidoti L, MasComa S, et al. Fascioliasis transmission by Lymnaea neotropica confirmed by nuclear rDNA and mtDNA sequencing in Argentina. Vet Parasitol. (2009) 166:73-9. doi: 10.1016/j.vetpar.2009.0 8.001

17. Huson KM, Oliver NAM, Robinson MW. Paramphistomosis of ruminants: an emerging parasitic disease in Europe. Trends Parasitol. (2017) 7:2. doi: 10.1016/j.pt.2017.07.002

18. Maitra A, Yadav CL, Sanjukta RK. Seasonal prevalence of paramphistomosis in domestic ruminants in different agro-climatic zones of Uttarakhand, India. Asian Pacific J Trop Dis. (2014) 4:S748-53. doi: 10.1016/S2222-1808(14)60720-9

19. O'Shaughnessy J, Garcia-Campos A, McAloon CG, Fagan S, de Waal T, McElroy $M$, et al. Epidemiological investigation of a severe rumen fluke outbreak on an Irish dairy farm. Parasitology. (2018) 145:94852. doi: $10.1017 /$ S0031182017002086

Conflict of Interest: The authors declare that the research was conducted in the absence of any commercial or financial relationships that could be construed as a potential conflict of interest.

Copyright (C) 2021 de Waal and Mehmood. This is an open-access article distributed under the terms of the Creative Commons Attribution License (CC BY). The use, distribution or reproduction in other forums is permitted, provided the original author(s) and the copyright owner(s) are credited and that the original publication in this journal is cited, in accordance with accepted academic practice. No use, distribution or reproduction is permitted which does not comply with these terms. 